Rev. Latinoam. Psicopat. Fund., São Paulo, v. 14, n. 3, p. 485-498, setembro 2011

\title{
A psicopatologia como uma experiência da alma*
}

Anna Paula Zanoni

Carlos Augusto Serbena

\begin{abstract}
Este trabalho teórico apresenta a visão do psicólogo arquetípico James Hillman sobre a psicopatologia. Ele defende que "patologizar" é um movimento da psique válido, necessário e autêntico, que permite um encontro com a alma e com os sentidos e que deve ser compreendido metaforicamente. Sua visão se contrapõe ao modelo médico e nominalista dominante, que tem uma visão literal da psicopatologia e que acaba por afastá-la dos sentidos, da alma e do próprio sujeito. A crítica maior de Hillman é sobre a relação literal da psicologia com as palavras e termos psicopatológicos.
\end{abstract}

Palavras-chave: Psicologia arquetípica, psicopatologia, loucura, alma

* Baseado em monografia de graduação intitulada A psicopatologia como uma experiência da alma, apresentada em novembro de 2007 na Universidade Federal do Paraná. 


\section{A psicopatologia}

O termo psicopatologia é, em geral, utilizado para se referir ao estudo das doenças mentais, abrangendo desde a perspectiva descritiva e sintomática até a teoria da origem e da manutenção dos funcionamentos psíquicos chamados mórbidos (Pereira, 2002). Entretanto, ele abrange uma série de diferentes definições, cada qual relacionada a um contexto, seja médico, psicológico, ou, ainda, ligado a distintos olhares dentro da própria psicologia.

Atualmente, a psicopatologia é estudada principalmente pela psiquiatria e pela psicologia. Entretanto, o desenvolvimento de diferentes correntes e conceituações acerca do psicopatológico, trazem a possibilidade, segundo Beauchesne (2002), de uma ruptura entre as diferentes tendências, até mesmo do desaparecimento das referências psicopatológicas. Passa-se, então, a repensar o fenômeno psicopatológico e também os modelos que caracterizam cada uma dessas diferentes tendências, principalmente o modelo médico que tentou unificá-las, normalizando e classificando o indivíduo que adoece. Surgem questionamentos sobre esse modelo, enfatizando a ótica das singularidades e do processo psicopatológico como uma possibilidade de restabelecer a saúde psíquica e não mais como degenerador.

Segundo Ceccarelli (2005), a palavra psicopatologia é composta por três palavras gregas: psychê, pathos e logos. Psychê resultou em psique, psíquico, psiquismo e alma. Pathos em paixão, excesso, passagem, passividade, sofrimento, assujeitamento e patológico. E logos, em lógica, discurso, narrativa e conhecimento. Psico-pato-logia poderia ser, então, um discurso ou um saber sobre a paixão da alma. Ou seja, um discurso representativo a respeito do sofrimento ou do padecer psíquico. 
Para o contemporâneo psicólogo arquetípico James Hillman¹ (1999), a palavra pathos também representa algo que se experimenta, uma comoção e a capacidade de comover-se, assim como as trocas que a alma sofre. Para ele, a patologia está presente na vida de todas as pessoas e o sofrimento é a sua imagem comum. Ela representa um movimento da psique (ou da alma) válido, autêntico e necessário.

Trata-se de um olhar diferenciado do tradicional modelo médico de classificação das doenças mentais - representado, atualmente, pelos conhecidos manuais, como o DSM (Manual de Diagnóstico e Estatística de Transtornos Mentais da Associação Psiquiátrica Americana) e o CID (Classificação Internacional de Doenças) - dominantes nos discursos dos profissionais da área da saúde e, inclusive, da psicologia.

Uma das grandes críticas que se faz a esses manuais, principalmente pelas abordagens psicológicas, "é o fato de não levar(em) em conta a subjetividade tanto daquele que está sendo 'classificado' quanto daquele que classifica: o olhar de quem olha não é imune à sua própria organização subjetiva" (Ceccarelli, 2005, p. 473). De forma semelhante, James Hillman compartilha dessa ideia e a desenvolve a partir de um ponto de vista: o da alma.

A relação da psicologia com a psicopatologia, como acredita Hillman (1975, 1983), pode proporcionar diversos sentidos ao sofrimento humano. Para ele, os chamados fenômenos psicopatológicos podem ser vistos de uma forma diferente da tradicional, desvinculada das ideias de algo errado ou de pecado e da conotação moral ou classificatória. Essa atitude possibilita uma elaboração e uma significação particular dos fenômenos vividos pelo indivíduo que sofre, transformando acontecimentos em experiências. Em termos poéticos, esse cuidado com relação à psicopatologia é uma forma de cultivo da alma (soul-making), pois permite que ela trabalhe a si mesma à sua maneira.

Neste sentido, o trabalho da psicologia, de acordo com Hillman (1975), deve ser o de oferecer uma solução e encontrar um lugar para a alma dentro do seu próprio campo de estudo, insistindo nos termos "profundidade" e "intensidade", pois eles tratam de experiências subjetivas ou vivenciais. Não devem ser entendidos como conceitos teóricos, pois os indivíduos sentem ou vivenciam a

1. James Hillman é um psicólogo nascido nos Estados Unidos, em 1926, considerado um pós-junguiano e um pós-moderno. Estudou em Paris, na Sorbonne, no Trinity Colege de Dublin e na Universidade de Zurique. Em 1959, obteve seu Ph.D nesta última universidade e ganhou o diploma de analista no Carl Gustav Jung Institute, em Zurich, tornando-se Diretor de Estudos do instituto por dez anos (Hillman, 1993a). Os trabalhos de Hillman refletem a variedade de áreas de suas investigações. Além de escrever sobre as questões com que a psicologia se ocupa, ele também faz uma análise da própria psicologia. 
profundidade e a intensidade de suas existências, relacionamentos, afetos e sentimentos, e isto é a base para constituir uma existência significativa.

\section{A alma como metáfora do humano}

Desse modo, Hillman $(1983,1999)$ defende que metáfora primária da psicologia deve ser a alma, que deve ser compreendida como uma perspectiva e um ponto de vista, e refere-se a uma metáfora da profundeza, da interioridade e da descida em sentido vertical aos significados. Ela não deve ser definida, mas imaginada. "Quando tentamos defini-la, afastamo-nos da sua natureza indefinível" e "utilizamos o intelecto onde ele não cabe" (1985, p. 17).

Hillman (1975) aponta três aproximações na tentativa de compreender o termo alma:

Em primeiro lugar, alma faz referência à transformação, por aprofundamento, dos acontecimentos em experiências. Em segundo lugar, a significação que a alma faz possível, tanto no que diz respeito ao amor quanto à inquietude religiosa, procede de sua especial relação com a morte. E, em terceiro lugar, por alma quero dar a entender as possibilidades de imaginação presentes na nossa natureza, a experiência através da especulação reflexiva, o sonho, a imagem e a fantasia, essa modalidade que reconhece toda realidade como primordialmente simbólica ou metafórica. (p. 39; tradução livre)

O termo "alma" é também utilizado de forma intermitente com a palavra "psique" que provém da figura mítica grega Psiquê - e que, segundo Hillman (1993b), é um termo mais moderno e mais próximo da biologia - e com a palavra anima, derivada do latim. A preferência pelo uso da palavra "alma", diferentemente de muitas psicologias que a evitam para se afastar do sentido mais comum e ligado à religião, ocorre propositadamente para aproximá-la de algo incognoscível, que está além da compreensão formal e que se afasta do cientificismo (1983).

Alma, anima e psique trazem a ideia de algo que envolve o ser humano e não somente algo que este possui. Elas também estão em tudo e em todos os lugares, na interioridade de todas as coisas e significam um movimento que situa o homem dentro delas e que revê toda a atividade humana como psicológica. Toda realidade concreta, nessa perspectiva, torna-se também uma realidade psicológica (1993b).

Ao afirmar que a metáfora primária da psicologia deve ser a alma, Hillman (1983) tem a intenção de dizer que o logos da alma é a metáfora e que se deve reconhecer que todas as afirmações da psicologia sobre a alma são metáforas, passando, assim, da preocupação da definição do termo para uma possibilidade imaginativa e não uma substancialidade. 


\section{A alma e a "patologização"}

Hillman (1999) introduz o neologismo "patologizar" a fim de designar a capacidade autônoma da psique para criar enfermidades, morbidades, desordens, anormalidades e sofrimentos em qualquer aspecto de sua conduta, assim como para experimentar e imaginar a vida através desta perspectiva deformada e afligida. A sua intenção é mostrar a necessidade psicológica da alma de patologizar, referindo-se a esse movimento da psique como algo válido, autêntico e necessário, que permite um contato com o material inconsciente.

A patologia é o lugar que mantém a pessoa na alma, aquele tormento, aquela torção a qual você não pode simplesmente ignorar, não pode simplesmente seguir adiante de uma maneira natural, pois há algo quebrado, torcido, doendo, que força uma reflexão constante. (1984b, p. 32; tradução livre)

Desse modo, patologizar é uma forma de libertar a alma da identificação com o ego e com os deuses ou imagens arquetípicas que servem de modelo ao ego. Serve para que a consciência da alma de si mesma seja diferente da do ego, obedecendo às suas próprias leis de representação metafórica. A metáfora é uma modalidade de discurso que permite à alma falar de si mesma (1999).

A patologia revela os poderes que estão além da vontade e do controle do ego, ou seja, revela a entrada dos "deuses" na psique, os quais mostram que cada dificuldade pode pertencer a vários deuses e ser fantasiada de várias maneiras diferentes. A mitologia, nesse caso, apresenta-se como uma narrativa dos mitos que a alma vive (1988).

A individualidade apresenta inúmeros aspectos psicopatológicos, tais como depressões, manias, desejos, ansiedades, ilusões, compulsões e perversões, os quais são aspectos da alma que precisam ser reconhecidos. Estes são os deuses. Hillman (1984a, 1999) propõe que talvez o grande medo que as pessoas sentem em ser o que realmente são, deve-se, em parte, ao temor do aspecto psicopatológico da individualidade. É um medo proveniente da fantasia egoica de autodominação presente na sociedade de hoje que vê, na patologia, algo que afeta a imagem desejada e maníaca de indivíduos saudáveis, felizes e bem-sucedidos.

A patologia produz uma intensa consciência da alma, isto é, da subjetividade ou da realidade psíquica, ao permitir que as partes sãs e normais possam ver o que habitualmente não veem. É uma forma pela qual se estabelece uma relação com a complexidade psíquica, pois como afirma Hillman (1999) "em meu sintoma está minha alma" (p. 223).

A grande questão que esse autor traz para a reflexão é conceber a psicopatologia como uma necessidade psicológica, e não como algo anormal, um desvio ou equívoco. Isto porque ela, a psicopatologia, não está presente somente 
nos momentos de crises, mas também na vida cotidiana, na consciência dos indivíduos mortais e no sentimento de singularidade que inclui a sensação de loucura individual (1999).

As vidas normais são construídas em meio a fantasias individuais do que é a enfermidade mental, o louco, o demente. As páginas dos manuais psiquiátricos oferecem a todos que as procuram critérios para identificação de enfermidades psiquiátricas. Ainda que esses critérios variem entre as culturas e as épocas, as fantasias da patologização, entretanto, sempre serão as mesmas, pois são de caráter arquetípico - universal ou coletivo - e, desse modo, presentes em todos os seres humanos de forma atemporal. O que muda em diferentes contextos são os conteúdos que definem e reconhecem essas fantasias. As noções sobre o que é uma pessoa transtornada remetem a uma imagem da psicopatologia, mas não são a verdadeira descrição da loucura. Essa descrição é variável no contexto de cada alma e seus conteúdos dependem, em parte, da ideia dominante do que é a sensatez.

\section{Uma crítica ao modelo médico e nominalista da Psicopatologia: a literalização da experiência da alma}

A psicopatologia, no sentido psicológico de uma experiência necessária para o aprofundamento da alma, pode ser negada, segundo Hillman (1999), de várias formas. Dentre elas, aponta a negação niilista que, resumidamente, parte do nada (nihil) para defender que os fatos da psicopatologia são uma ficção positivista e não uma realidade existencial, deixando o que está enfermo de lado. Também fala sobre a negação transcendente, representada pela psicologia humanista e que acaba por deixar na sombra os aspectos obscuros e profundos da alma, os quais são vistos como "valores regressivos". Por fim, discorre sobre a negação nominalista, focada neste trabalho.

A negação nominalista da psicopatologia centra-se nas palavras, na nominação e na classificação das doenças psíquicas. A psicologia pode ser considerada nominalista quando considera os termos apenas como descrições de fatos, comportamentos, atitudes ou sentimentos que podem ser descritos de outra forma. Assim, as imagens ou os quadros da psicopatologia podem ser modificados junto com as palavras, e a depressão, por exemplo, torna-se uma etiqueta e não uma experiência vital.

De acordo com Hillman (1999), o modelo nominalista é uma tentativa de classificar a mente, assim como se classificam as plantas e os animais, o que exige o domínio de um vocabulário técnico. 
Esse psicólogo, entretanto, não pretende descartar os termos psicopatológicos e nem desestimar a importância fundamental atual e histórica que conquistaram. Não se pode negar a grande relevância que o nominalismo tem e nem descontextualizá-lo da necessidade pela qual surgiu e que estava relacionada às explicações não racionais, tais como maldições, bruxarias e demônios, no início do período Iluminista (1999).

Muitos termos do campo de estudo da psicologia, tais como "neurose" e "complexos", funcionam como ferramentas para diferenciar e refletir sobre determinadas realidades da alma. Sem as classificações, as denominações e as objetivações - que são consideradas exteriores ao sujeito - não seria possível acumular conhecimentos e nem fazer previsões.

Entretanto, a principal tarefa do psicólogo, para Hillman (1999), é conseguir manter a ligação entre essas questões externas - relacionadas à coletividade (o termo neurose, por exemplo, é um termo geral e externo à individualidade do sujeito) - e o interior, não perdendo de vista a metáfora básica: a alma.

O que Hillman pretende ao refletir sobre o tema é desvincular as palavras técnicas - nominalistas - do pensamento médico literal e mostrar que, nesse contexto, elas acabam por carecer de uma necessidade psíquica inerente, pois não fazem referência ao que uma pessoa tem, ao que ela é ou às suas fantasias. A necessidade que o nominalismo tem de definir os termos, estabelece o que algo é e o que não é, eliminando o que não pertence. Sua lógica acredita que quanto mais exatamente pode-se definir algo, mais esse algo pode ser conhecido. Entretanto, grande parte do que diz respeito à alma - e entre ela está a psicopatologia - é ambígua e não pode ser completamente conhecida, tornando qualquer definição prematura (1993b).

Os termos técnicos, que em muitos casos tornaram-se insultos populares, muitas vezes são aplicados em forma de etiquetas nas pessoas, sem conexão com a realidade psíquica (1999).

Etiquetas tais como "psicopata" ou "maníaco-depressivo", ainda que introduzam uma claridade intelectual, selam também em recipientes herméticos o conteúdo do que se nomeia, e a pessoa assim nomeada é relegada a uma estante com o rótulo de "psicologia anormal". (p. 155; tradução livre)

Uma etiqueta diagnóstica, como afirmou Hillman (1999), é um peculiar enlaçar de ao menos quatro séries de circunstâncias: uma nomenclatura, um contexto, um médico e um paciente. Desde o início do interesse da humanidade pelo estudo das psicopatologias é possível perceber que as mudanças nas nomenclaturas são sutis e que aquilo que se nomeia permanece incerto.

A grande questão colocada por Hillman (1993b) é que essas classificações geralmente não apontam a lugar nenhum por não adentrarem na alma. As palavras 
utilizadas pelo modelo médico não fazem relação com os fatos que supostamente representam. São nomina vazios e não têm nenhuma razão intrínseca com as doenças que as definições descrevem. Podem, inclusive, descrever uma patologia sem haver, em absoluto, qualquer enfermidade. As descrições acabam por não apresentar nada real porque pertencem a uma lógica adequada para os objetos inanimados e despersonificados, para a ciência e não para o mundo da alma, do qual faz parte a psicopatologia.

As palavras utilizadas para descrever suas aflições requerem uma subjetividade que expresse e contenha as dolorosas e estranhas afecções da alma, se realmente querem se ajustar ao que pretendem descrever. Entretanto, para isso necessitamos de uma psicologia arquetípica. Enquanto não descobrimos a persona arquetípica presente nestas palavras, dando-lhes um significado psicológico ao conectar as síndromes com os arquétipos, o nominalismo encherá seus termos vazios personalizando-os com gente real. (1999, p. 155; tradução livre)

O que Hillman (1999) pretende dizer é que esses termos se aderem às pessoas e estas acabam por converter-se em "alcoólicas", "suicidas" ou "esquizofrênicas", parecendo assim fortalecer essas palavras e conferir uma realidade psíquica empírica a elas. Entretanto, essas pessoas apenas recebem etiquetas classificatórias e nenhum movimento de profundidade e interioridade é realizado.

A busca pelo tratamento médico adequado ou pela cura imediata da doença literaliza a patologização, apresentando um modelo que já está pronto na mente antes mesmo de o caso se mostrar. Na perspectiva arquetípica não se pode mais falar em "tratamento psicológico", pois tratar significa tentar separar a alma e a patologia. A palavra cuidado se mostra muito mais adequada ao objetivo do cultivo da alma (1993b, 1999).

"Quando somos psicológicos com respeito à patologização, não a estamos tratando; quando tratamos a patologização, não estamos sendo psicológicos com respeito a ela" (1999, p. 177; tradução livre). Ser psicológico significa cuidar da alma e não tratá-la; servir a ela e deixá-la guiar. É se manter dentro daquilo que é confuso, mórbido e fantástico, abandonando o modelo clínico, racional e físico, e adotando em seu lugar o método da imaginação, ou seja, é estar no meio da desordem ao mesmo tempo em que se observa o que está ocorrendo numa perspectiva mítica. "A loucura nos ensina o método" (p. 178; tradução livre). O modelo médico e nominalista lida com as patologias como problemas a serem curados, sanados, tratados. Não vê o patologizar como uma forma pela qual a alma ou psique trabalha a si mesma.

Todo campo deve ter sua própria linguagem e a psicologia necessitou de um modo de falar que fosse adequado ao seu domínio. Entretanto, a crítica de Hillman 
reside sobre a relação literal da psicologia com as palavras: a crença de que as palavras se referem diretamente às coisas (1984b, p. 180).

O Iluminismo, ao criar os nomina, captou elementos no ar da fantasia, racionalizando-os, enrijecendo-os e destacando-os de sua raiz mítica, visto que os nomina também são expressões da imaginação mítica. Dessa forma, a intenção da psicologia arquetípica é resgatar a substância arquetípica dos nomina aquela que surge da fantasia e que se perpetua no tempo através das várias imagens "loucas" - através da imaginação. Assim, os termos perdem o seu nominalismo puramente descritivo e passam a ser conceitos vistos como metáforas (1984b).

Para Hillman (1984b), os nomina podem ser preservados, mas com a condição de não serem acreditados do mesmo modo que antes, a fim de evitar o risco de "perda da alma", isto é, de realizar uma literalização das experiências, significando a predominância do pensamento egoico e racional. Consequentemente, isto não permite o aprofundamento das imagens da psique e o trabalho pessoal de estabelecer relações significativas e laços afetivos consigo próprio, com os outros e com o mundo.

A psicopatologia é representada pela distorção, o que pressupõe que existe algo que é considerado ideal ou normal e que pode sofrer uma deformação. Esses ideais e essas normas proporcionam uma série de meios para ver a patologização, mas não devem ser interpretados como uma série de instrumentos para medi-la. Assim, a norma ideal perde sua importância no que se refere ao valor de uma experiência patologizada. As normas e os nomina são modos perceptuais de ver os contrastes e ajudam a notar os desvios com mais nitidez, assim como a perceber rapidamente o alto grau de patologização de um fato. Porém, o valor psicológico da psicopatologia não é expresso nem pela norma ou pelo desvio, mas pela aflição manifestada pelas imagens fantásticas. Isso porque a individualidade é essencialmente desigual, é diversa e está relacionada à complexidade da composição da alma (1984b, 1975).

O próprio conceito de individuação proposto por Jung traz essa ideia: a da diferenciação das partes da psique em relação ao todo. Isso significa que não é possível estabelecer uma norma nem sequer para um mesmo indivíduo, pois uma norma requer uma vigência absoluta e um indivíduo é guiado por inúmeras personas e deuses que seguem diferentes caminhos. A aflição manifestada, por sua vez, é a forma como os deuses alcançam os indivíduos. Hillman (1999) afirma que dentro da aflição existe um complexo, que dentro deste existe um arquétipo que, por sua vez, faz referência a um deus. Dessa forma, patologizar através da aflição abre as portas da psique para que os deuses entrem (1999).

Não é possível afirmar a existência de um ideal de homem e de uma norma de homem, como o modelo médico propõe. O estudo profundo da patologização

Rev. Latinoam. Psicopat. Fund., São Paulo, v. 14, n. 3, p. 485-498, setembro 2011 
implica a derrubada de qualquer psicologia normativa derivada de critérios externos, não pertencentes ao indivíduo singular. A saúde idealizada é

... uma imagem sobre-humana de um homem-Deus que domina as fantasias de um ego que vê a si mesmo como um herói de mármore, intacto e imaculado, talhado em uma só peça, perpetuamente equilibrado sobre seu centro de gravidade. (1999, p. 204; tradução livre)

O sintoma é o que afasta os seres humanos da fantasia da saúde idealizada e que deforma, humilha e os transforma em homens psicológicos, com consciência da alma e com o poder do ego relativizado. A reflexão acerca do sintoma é essencial: o que ele significa? O que está acontecendo, que modelo arquetípico está presente, que ideia está se apresentando nesse momento, qual deus está no governo? Enfim, a questão central, no lugar dos clássicos "por quês" ou do "como" é: o que é isso que acontece? (1999).

Essas perguntas permitem que os acontecimentos digam o que são, sem buscar causas, soluções, explicações ou propósitos. Trata-se de uma forma de aprofundamento e interiorização, que acolhe a psicopatologia e permite que ela seja ouvida e elaborada. "Patologizar incita a psicologizar" (1999, p. 186) e "psicologizar"

... é analisar não somente as nossas personalidades e nosso material psicológico, como nossos sonhos e problemas, mas é também analisar as ideias com as quais examinamos nossas personalidades e nosso material psicológico. Mais ainda: a psicologização arquetípica significa examinar nossas próprias ideias, remetendo-as aos arquétipos; significa observar as molduras da nossa consciência, as jaulas que ocupamos e as barras de ferro que formam as grades e as defesas da nossa percepção. (p. 267; tradução livre)

A psicologização significa a produção de reflexões distintas daquilo que está evidente, que busca uma intenção interior, um mecanismo oculto, algo que não é possível enxergar através das lentes habituais. Ela faz com que através do ato reflexivo as próprias ideias se questionem para que possa transparecer sua importância para a alma, o que também é um cultivo da alma. Ela transforma qualquer ação literal - política, científica, pessoal - em uma representação metafórica. Os problemas passam a ser vistos como fantasias literalizadas, as quais não se tornaram visíveis e não vieram à luz anteriormente.

\section{Considerações finais}

A psicopatologia passou por diversos caminhos até adquirir a forma classificatória e nominalista predominante nos discursos médicos e psicológicos

Rev. Latinoam. Psicopat. Fund., São Paulo, v. 14, n. 3, p. 485-498, setembro 2011 
de hoje. Passou por olhares transcendentais, românticos, interessados, indiferentes e atualmente se encontra sob o olhar racionalista. Entretanto, se a psicologia se atém somente a esse olhar, de forma unilateral, conforme Hillman alerta, ela acaba por se afastar da sua tarefa principal: cuidar do discurso da alma, porque a alma não se expressa de forma objetiva e literal, mas metaforicamente.

A sociedade moderna ignora os aspectos relativos à alma: a inferioridade, a interioridade, a profundidade das experiências, as fraquezas e as inseguranças. Não há lugar para a alma nos interesses modernos. Pouco se permite imaginar ou fantasiar: os acontecimentos tornam-se fatos literais e sem profundidade. Entretanto, a alma não pode ser simplesmente ignorada, porque é uma perspectiva manifestada em todas as coisas e que reclama por seus interesses, como é o caso da psicopatologia, que aponta para uma necessidade.

Nessa perspectiva da alma, o indivíduo passa a compreender e admitir que não é totalmente autônomo, ou, ainda, que existem outras forças além da vontade, da razão e da situação socioeconômica que são responsáveis pela sua vida. A separação entre os sentimentos, o mundo interno e a suposta razão apresenta-se como insustentável. Os seres humanos possuem e são possuídos por muitos deuses que governam seus destinos, que transformam toda realidade concreta em realidade psicológica. São seres complexos que possuem uma diversidade psíquica e a psicopatologia - enquanto uma possibilidade de contato com a alma, de quebra da noção autocentrada de "eu" da modernidade -, é uma clara representante dessa complexidade.

Hillman nos mostra que não se pode pensar que as imagens da psicopatologia não deveriam existir, ou pensar que sempre requerem uma ação porque sempre diagnosticam um perigo. Se há algo errado ou perigoso em relação às fantasias patologizadas, esse algo é precisamente a maneira de tratá-las. A atitude em relação a elas pode se apresentar como um caminho de construção ou destruição.

Desse modo, patologizar é um movimento válido, necessário e autêntico, que permite que a alma fale de si mesma na sua própria linguagem. Com isso, Hillman propõe uma revisão da psicologia, mostrando a importância de se "desliteralizar" a visão que ela tem da psicopatologia e adoção de uma visão metafórica, pois é dessa forma que a alma se expressa.

Para ele, a psicologia não precisa abandonar os termos que criou ou que emprestou da medicina, e nem se desfazer dos conhecimentos proporcionados pelo modelo médico e nominalista. O que ela precisa fazer é sempre manter a conexão entre esses conhecimentos exteriores e o mundo interior de cada pessoa, sem tentar explicar ou definir as aflições, mas simplesmente ouvindo o que elas têm a dizer. A partir daí, a psicologia torna-se capaz de adentrar nas profundidades da alma e de ampliar o espaço psicológico. 
A consciência do ego não é capaz de refletir toda a realidade e nem todos os seus aspectos. Um caminho apontado por Hillman é conhecer as próprias imagens, passear pela alma, pela profundidade do espaço psicológico e não somente pela sua extensão. A alma tem se encolhido porque sua imaginação está enfraquecida, devido ao pouco espaço dado para fantasiar ou refletir sobre as coisas.

A unilateralidade das perspectivas médicas ou teológicas não dão lugar para a imaginação, pois reduzem-na a simples fantasia e fazem-na parecer irreal, sem relação com o mundo e, nesse sentido, é "desalmada", pois "a aventura humana consiste em vagar pelo vale do mundo com o fim de fazer a alma. Nossa vida é psicológica, e o propósito da vida é criar uma psique com ela, encontrar conexões entre a vida e a alma" (1999, p. 38; tradução livre).

\section{Referências}

Avens, R. Imaginação é realidade. Petrópolis, RJ.: Vozes, 1993.

Beauchesne, H. História da psicopatologia. 2. ed. São Paulo: Martins Fontes, 2002.

Ceccarelli, P. O sofrimento psíquico na perspectiva da psicopatologia fundamental. Psicologia em Estudo. Maringá, v. 10, n. 3, 2005. Disponível em: <http:// www.scielo.br/scielo.php?script=sci_arttext\&pid=S141373722005000300015\&lng=pt\&nrm=iso $>$ Acesso em: 23/3/07.

Hart, D.L. Introdução: Jung e os pós-junguianos. In: Young-EInsendrath, P.; Dawson, I. (Orgs.). Manual de Cambridge para estudos junguianos. Porto Alegre: Artmed, 2002. p. 101-125.

Hillman, J. (1975). Re-imaginar la psicología. Madrid: Ediciones Siruela, 1999. . (1983). Psicologia arquetípica. São Paulo: Cultrix, 1988.

. Uma busca interior em psicologia e religião. São Paulo: Paulus, 1984a.

. O mito da análise: três ensaios de psicologia arquetípica. Rio de Janeiro: Paz e Terra, 1984b. . Anima: anatomia de uma noção personificada. São Paulo: Cultrix, 1985. . Cidade e alma. São Paulo: Studio Nobel, 1993a. . Suicídio e alma. Petrópolis, RJ.: Vozes, 1993b.

Pereira, M.E.C. Psicopatologia fundamental e psiquiatria. In: QueIroz, E.F.; Silva, A. R.R. (Orgs.). Pesquisa em psicopatologia fundamental. São Paulo: Escuta, 2002. p. $28-49$. 
SAmuels, A. Introdução: Jung e os pós-junguianos. In: Young-Einsendrath, P.; Dawson, I. (Orgs.). Manual de Cambridge para estudos junguianos. Porto Alegre: Artmed, 2002. p. 27-35.

\section{Resumos}

(Psychopathology as experience of the soul)

This theoretical discussion presents the views of the archetypical psychologist James Hillman on psychopathology. He says that "becoming pathological" is a correct, necessary and authentic movement of the psyche that provides an encounter with the soul and with meanings, and that must be understood metaphorically. His view is in disaccord with the medical and nominal model, which has a literal view of psychopathology and sets aside meanings, the soul and even the person. Hillman's strongest criticism is toward the literal relationship of psychology with terms and concepts used in psychopathology.

Key words: Archetypical psychology, psychopathology, madness, soul

(La Psychopathologie comme une expérience de l'âme)

Ce document présente la vision du psychologue archétypique James Hillman sur la psychopathologie. Il défend que "pathologiser" est un mouvement valide, approprié et authentique de la psyché qui permet une rencontre avec l'âme et les sens et qui doit être compris métaphoriquement. Son point de vue est opposé au modèle médical et nominaliste dominant qui présente à son tour une vision littérale de la psychopathologie et qui l'éloigne des sens, de l'âme et du sujet lui-même. La plus importante critique de Hillman concerne le rapport littéral de la psychologie avec les mots et les termes psychopathologiques.

Mots clés: Psychologie archétypique, psychopathologie, folie, ame

(La psicopatología como experiencia del alma)

Este artículo presenta la visión teórica de la psicopatología del psicólogo arquetípico James Hillman. El defiende que "patologizar" es un movimiento válido de la psiquis, necesario y auténtico, que permite un encuentro con el alma y con los sentidos, y que debe ser entendido metafóricamente. Su visión se contrapone al modelo médico y nominalista dominante, que tiene una visión literal de la psicopatología y que termina apartándola de los sentidos, del alma y de mismo sujeto. La mayor crítica que hace Hillman se refiere a la relación literal de la psicología con las palabras y los términos psicopatológicos.

Palabras clave: Psicología arquetípica, psicopatología, locura, alma 
Citação/Citation: ZanonI, A.P.; Serbena, C.A. A psicopatologia como uma experiência da alma. Revista Latinoamericana de Psicopatologia Fundamental, São Paulo, v. 14, n. 3, p. 485-498, set.2011.

Editor do artigo/Editor: Prof. Dr. Manoel Tosta Berlinck

Recebido/Received: 9.9.2010 / 9.9.2010 Aceito/Accepted: 25.11.2010 / 11.25.2010

Copyright: @ 2009 Associação Universitária de Pesquisa em Psicopatologia Fundamental/ University Association for Research in Fundamental Psychopathology. Este é um artigo de livre acesso, que permite uso irrestrito, distribuição e reprodução em qualquer meio, desde que $\mathrm{o}$ autor e a fonte sejam citados/This is an open-access article, which permits unrestricted use, distribution, and reproduction in any medium, provided the original author and source are credited.

Financiamento/Funding: Os autores declaram não ter sido financiados ou apoiados/The authors have no support or funding to report.

Conflito de interesses/Conflict of interest: Os autores declaram que não há conflito de interesses/The authors declare that has no conflict of interest.

\section{Anna Paula Zanoni}

Psicóloga Clínica graduada em psicologia pela Universidade Federal do Paraná - UFPR (Curitiba, PR, Br) e especialista em Psicologia Analítica pela Pontifícia Universidade Católica do Paraná - PUC-PR (Curitiba, PR, Br).

Rua Des. Hugo Simas, 1110 - Bom Retiro

80520-250 Curitiba, PR, Br

Fone: (41) 9929-4730

e-mail: annapaulazanoni@yahoo.com.br

\section{Carlos Augusto Serbena}

Professor do Departamento de Psicologia da Universidade Federal do Paraná - UFPR (Curitiba, PR, Br); Doutor em Ciências Humanas pela Universidade Federal de Santa Catarina - UFSC (Florianópolis, $\mathrm{SC}, \mathrm{Br}$ ).

Praça Santos Andrade, 50 - Centro

UFPR Departamento de Psicologia

80060-246 Curitiba, PR

Fone: (41) 9191-6886

e-mail: caserbena@yahoo.com 